\title{
Strength of a clay soil and soil-cement mixture with resin
}

$1 \quad$ Ali R. Estabragh BEng, MSc, PhD Assistant Professor in Geotechnical Engineering, Faculty of Soil and Water Engineering, University of Tehran, Tehran, Iran

2 Mohammad Naseh BEng, MSc

Postgraduate Student, Faculty of Soil and Water Engineering, University of Tehran, Tehran, Iran
3 Iman Beytolahpour BEng, MSC Postgraduate Student, Faculty of Soil and Water Engineering, University of Tehran, Tehran, Iran

4 Akbar A. Javadi BEng, MSc, PhD

Associate Professor in Geotechnical Engineering, Computational Geomechanics Group, College of Engineering, Mathematics and Physical Sciences, University of Exeter, Exeter, UK
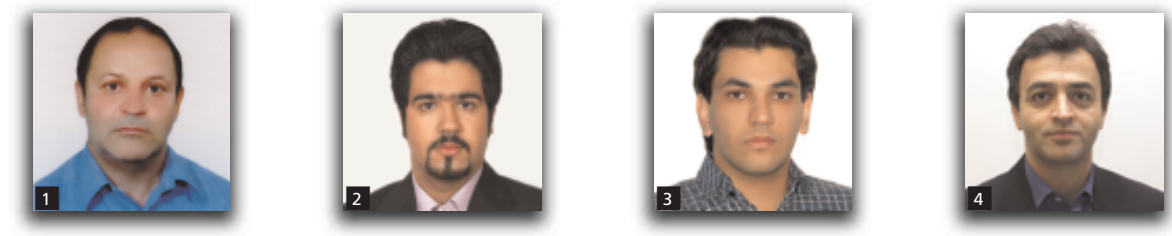

A series of laboratory experiments were carried out to investigate the effect of resin on the strength of a clay soil and soil-cement mixtures. One group of tests were carried out on samples of the clay soil that were prepared with different resin contents. Another group of tests were conducted on mixtures of soil-cement and soil-cement-resin with specified resin contents. The results show that adding more than $10 \%$ resin increases the strength of the soil, whereas at resin contents below $10 \%$ no significant effect was observed. The strengths of the samples of soil, soilcement mixture and soil-cement-resin mixture increased with increasing percentages of cement and resin. The results also show that the increase in strength is a function of percentage of agents and curing time.

\section{Introduction}

Problematic soils can generally be characterised as poor-quality materials. They usually have the potential to show undesirable engineering behaviour, such as high swell potential and shrinkage, high moisture susceptibility and low bearing capacity. Geotechnical engineers often have the choice of replacing the problematic soils with better-quality soils for construction or attempting to improve the engineering properties of the soils through a suitable soil stabilisation technique. Due to problems with the availability of good-quality materials, haul distance and economic considerations, stabilisation of the existing soils is often the preferred option for construction.

Stabilisation is commonly used to improve the mechanical properties (e.g. strength and stiffness) of soils. The improvement is effected by controlling the void ratio of soil by introducing a cementing agent or by injecting a substance to fill the pore volume. Chemical stabilisers are divided into two groups: traditional agents and non-traditional agents. Traditional chemical stabilisers such as lime, cement, fly ash or bituminous material have such effects as developing a cementitious bond between the particles or increasing the water resistance of the soil. Recently researchers have found that concentrated liquid agents such as petroleum-based emulsions and polymers can be used as materials for stabilisation. These are classed as non-traditional chemical stabilisers.
Soil stabilisation using traditional agents such as lime and cement is a topic that has been extensively researched and the number of publications dealing with lime and cement stabilisation is vast. Ingles and Metcalf (1972) explained the processes involved in treating soil with lime and indicated that adding lime to clay increases the strength and decreases the plasticity index of clay and that there is no significant decrease in the swell potential of active clays and the linear shrinkage values.

The cement agent developed as a result of mixing a small quality of cement with soil is identical to the cementation product developed by addition of lime. Cement stabilisation increases the compressive, tensile and flexural strength, durability and stiffness properties of soil (Al-Rawas et al., 2005; Bahar et al., 2004; Broms and Boman, 1978; Croft, 1967; Khair et al., 1991; Miller and Azad, 2000; Mitchell, 1976; Sezer et al., 2006; Tang et al., 2007).

A number of researchers such as Ajayi-Mejebi et al. (1991), Bolander (1999) and Tingle and Santoni (2003) used nontraditional agents as an alternative method for soil stabilisation. Scholen (1992) categorised non-traditional stabilisers into five groups and attempted to describe the reinforcement mechanisms for some of them. Ajayi-Mejebi et al. (1991) examined the mechanism of stabilisation of clay-silt soils with combination of an epoxy resin and a polyamide hardener. They found that the 
value of California bearing ratio (CBR) for a mixture of clay and silt increased when treated with $4 \%$ epoxy resin agent. Katz et al. (2001) and Rauch et al. (2002) investigated the effect of three non-traditional agents on treatment of a clay soil. Rauch et al. (2002) indicated that there was no significant improving effect of agents (enzymes) on the Atterberg limits, compacted density, shear strength or swell potential, while Katz et al. (2001) reported only minor changes in the mechanical behaviour of the soil.

Some researchers such as Afridi et al. (1994) and Gao et al. (2002) focused on certain aspects of mechanical behaviour such as strength and durability of resin-modified cement mortars and resin-modified concrete. In addition, a number of studies have been carried out on the effects of resin on soil-cement mixtures. Anagnostopoulos and Hadjispyrou (2004), Anagnostopoulos (2007) and Estabragh et al. (2011) suggested that acrylic resin can increase the strength of soil-cement mixture.

Acrylic resins have many advantages in comparison with other non-traditional chemical agents such as lignin (natural resin), phosphorus pentoxide and phosphoric acid. Acrylic resins are usually prepared in emulsion form with $40-60 \%$ solids; they are non-toxic and non-flammable. After curing they are not water soluble. Lignin has been used as an additive to soils for many years. It is available in powder form and in the form of sulfite liquid. It is used in both forms as an additive to soils. Lignin is water-soluble, hence its stabilising effects are not permanent. Phosphorus pentoxide is another agent that works extremely quickly - too quickly to allow for adequate mixing and compaction. One of the problems of this agent is its extremely toxic nature and the neutralising effect of trace amounts of calcium carbonate. Phosphoric acid is an effective agent for stabilising soil but it is extremely hazardous. Sodium hydroxide has been considered as an additive to cement as a stabiliser but it is caustic, being a strong alkali, and extremely corrosive to many materials and human tissues. As a result of these considerations, acrylic resins are preferable to other agents for soil stabilisation.

Review of the literature shows that a large amount of research has been carried out on the application of traditional stabilising agents. However, in spite of rapid development of existing nontraditional agents and introduction of new stabilisers, little research has been directed towards the use of non-traditional agents.

The aim of this work was to design and carry out a programme of experiments to study the effects of a non-traditional (resin) and traditional (cement) agents on the mechanical behaviour of a clay soil and also on the properties of soil-cement mixtures.

\section{Materials used and testing programme}

\subsection{Properties of materials}

The main materials that were used in this work were soil, cement, resin and water. The soil used in this experimental work was clay, consisting of $8 \%$ sand, $55 \%$ silt and $37 \%$ clay. The grain size distribution of the soil is shown in Figure 1. The physical and chemical properties of the soil are presented in Tables 1 and 2 . The standard compaction test showed that the optimum water content of the soil was $17.5 \%$, corresponding to a maximum dry unit weight of $17 \cdot 2 \mathrm{kN} / \mathrm{m}^{3}$. The soil is classified as clay with low plasticity (i.e. CL according to the Unified Soil Classification System (USCS)).

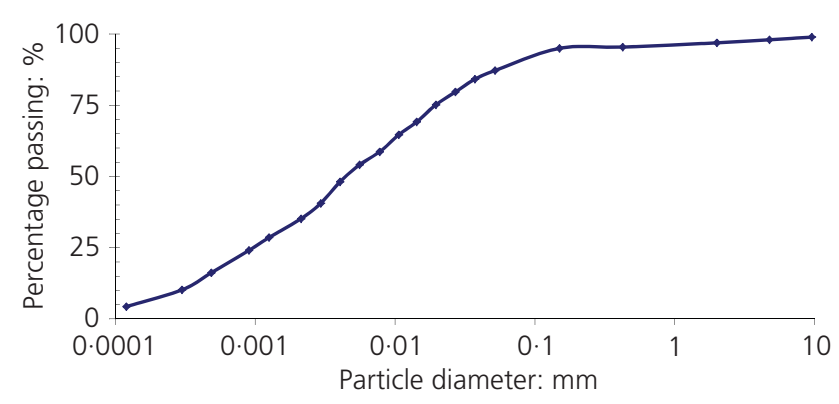

Figure 1. Grain size distribution curve

\begin{tabular}{lc}
\hline Property & Value \\
\hline Liquid limit: \% & $46 \cdot 0$ \\
Plastic limit: \% & $23 \cdot 0$ \\
Plasticity index Pl: \% & $23 \cdot 0$ \\
Specific gravity, $G_{s}$ & $2 \cdot 7$ \\
Optimum water content: \% & $17 \cdot 5$ \\
Maximum dry unit weight: $\mathrm{kN} / \mathrm{m}^{3}$ & $17 \cdot 2$ \\
Compression index, $C_{c}$ & $0 \cdot 7$ \\
Swelling index, $C_{s}$ & 0.08 \\
Table 1. Physical properties of the soil & \\
\hline
\end{tabular}

\begin{tabular}{lc}
\hline Chemical component & Amount \\
\hline $\mathrm{SO}_{4}{ }^{2-}:$ meq/L & $83 \cdot 00$ \\
$\mathrm{HCO}_{3}{ }^{-}:$meq/L & $4 \cdot 00$ \\
$\mathrm{CO}_{3}{ }^{2-}: \mathrm{meq} / \mathrm{L}$ & 0.60 \\
$\mathrm{Mg}^{2+}: \mathrm{meq} / \mathrm{L}$ & $10 \cdot 00$ \\
$\mathrm{Ca}^{2+}: \mathrm{meq} / \mathrm{L}$ & $24 \cdot 00$ \\
$\mathrm{~K}^{+}: \mathrm{meq} / \mathrm{L}$ & 0.33 \\
$\mathrm{CaCO}: \%$ & $10 \cdot 2$ \\
$\mathrm{OC}^{a}: \%$ & $0 \cdot 10$ \\
$\mathrm{pH}$ & $8 \cdot 00$ \\
Electrical conductivity: $\mu \mathrm{moh} / \mathrm{cm}$ & $10 \cdot 74$ \\
\hline
\end{tabular}

arganic content

Table 2. Chemical composition of the soil 
The cement used was Portland type 1 with specific gravity of $3 \cdot 15 \mathrm{~g} / \mathrm{cm}^{3}$ and Blaine fineness of $4200 \mathrm{~cm}^{2} / \mathrm{g}$. The physical and mechanical properties of the cement are shown in Table 3.

The commercial name of the resin that was used is Tarabeton. The resin is a non-cross-linking acrylic emulsion of a thermoplastic chemical substance with good binding properties. Typical properties of the resin used are presented in Table 4.

Drinking water was used for compaction, preparation of samples and hydration of cement. It had a $\mathrm{pH}$ of $7 \cdot 76$, chloride content of $17 \mathrm{meq} / \mathrm{l}$ and calcium + magnesium content of $9 \cdot 1 \mathrm{meq} / \mathrm{L}$.

\subsection{Sample preparation and testing}

Standard compaction tests were conducted on the natural soil and mixtures of soil-cement and resin-soil. The samples for the main tests were prepared by static compaction according to the optimum water content and maximum dry unit weight that were obtained from the standard compaction tests. To prepare soilcement samples, natural soil, cement and water were weighted with an accuracy of $0 \cdot 1 \mathrm{~g}$. They were mixed in a container and water was added up to the optimum water content. The mixture was kept in a sealed container for about $30 \mathrm{~min}$ for uniform distribution of moisture. The samples were prepared in a cylindrical mould by static compaction in three layers. Each layer was compacted at rate of $1 \mathrm{~mm} / \mathrm{min}$ until maximum dry density (according to the compaction test) was achieved. The length and diameter of the samples were $100 \mathrm{~mm}$ and $50 \mathrm{~mm}$, respectively.

\begin{tabular}{lc}
\hline Physical property & Amount \\
\hline Normal consistency: \% & $24 \cdot 4$ \\
Initial setting time: min & $21 \cdot 0$ \\
Final setting time: min & $145 \cdot 0$ \\
Compressive strength, 7 days: $\mathrm{kPa}$ & $30000 \cdot 0$ \\
Compressive strength, 28 days: $\mathrm{kPa}$ & $43000 \cdot 0$ \\
&
\end{tabular}

Table 3. Properties of cement

\begin{tabular}{lc}
\hline Property & Value \\
\hline Solid content:\% & $50 \cdot 00$ \\
$\mathrm{pH}$ & $7 \cdot 50 \pm 0 \cdot 5$ \\
Density: $\mathrm{g} / \mathrm{cm}^{3}$ & $1 \cdot 04$ \\
Mean particle size: $\mu \mathrm{m}$ & $0 \cdot 10$ \\
Surface tension: $\mathrm{mN} / \mathrm{m}$ & $42 \cdot 00$ \\
Tensile strength: $\mathrm{N} / \mathrm{mm}^{2}$ & $4 \cdot 00$ \\
Mechanical stability & Excellent \\
Appearance & Milky white liquid \\
Type & Non-cross-linking \\
Emulsifying system & Non-ionic \\
Table 4. Typical properties of Tarabeton resin
\end{tabular}

They were stored in a special cabinet at $25^{\circ} \mathrm{C}$ temperature and $95 \%$ relative humidity. For preparation of soil-resin and soilcement-resin samples the specified amount of resin was dissolved in water and added to the soil or soil-cement mixture to the optimum water content. The same procedure as used for preparing soil-cement samples was used for preparing soil-resin and soil-cement-resin samples.

\subsection{Compressive strength}

The unconfined compressive strength test is the most commonly used test for determination of mechanical properties of soilcement. The value of unconfined compressive strength is an indicator of the degree of reaction of the mixture (soil-cement, soil-resin and soil-cement-resin) and the rate of hardening. This kind of test provides a convenient basis for testing and is a quick and simple procedure for comparative analysis. Compressive strength serves as a criterion for determining minimum cement requirements for proportioning soil and cement. Because strength is directly related to density, this property is affected in the same manner as density by degree of compaction and water content. Unconfined compression tests were conducted on the samples of soil-resin, soil-cement and soil-cement-resin after curing times of 3, 7 and 28 days according to the ASTM D1633 standard (ASTM, 1983).

\section{Results and discussion}

The results of standard compaction tests for soil with $5 \%, 8 \%$ and $10 \%$ resin show that the optimum water content and maximum dry density are nearly the same as those of the natural soil. The maximum dry density for a soil-cement mixture increased and the optimum water content decreased with increasing cement content. These variations can be attributed to the change in the clay's behaviour due to hydration resulting from the reaction of cement with soil moisture and exchange of ions. These results are consistent with those reported by Croft (1967).

Figures 2 and 3 present typical results of mixtures of soil and resin after curing times of 3, 7 and 28 days for resin contents of $8 \%$ and $10 \%$, respectively. Figure 2 shows that the peak strength of the natural soil is about $280 \mathrm{kPa}$ at $3 \cdot 2 \%$ axial strain, but the

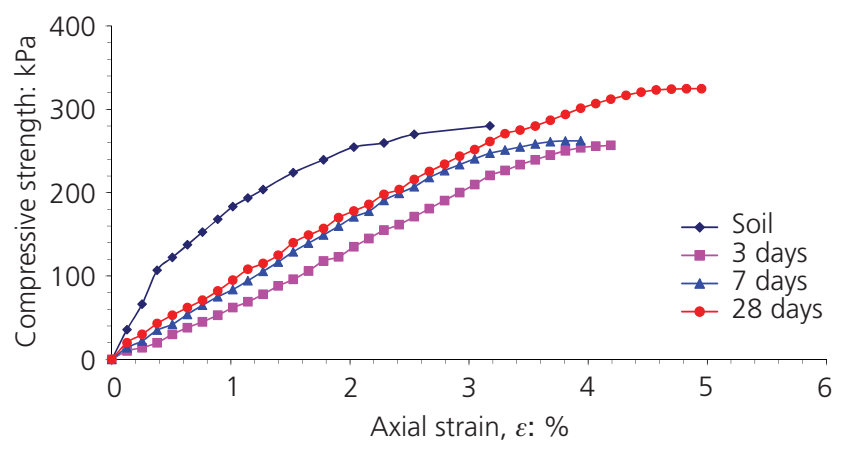

Figure 2. Stress-strain curves for a mixture of soil with $8 \%$ resin for different curing times 


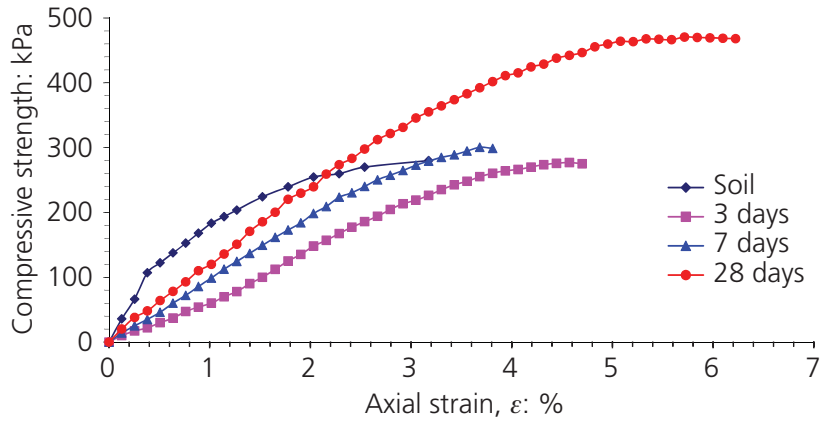

Figure 3. Stress-strain curves for a mixture of soil with $10 \%$ resin for different curing times

samples of soil and $8 \%$ resin after 3 and 7 days have strengths of 256 and $262 \mathrm{kPa}$ at strains of $4 \cdot 2 \%$ and $4 \%$, respectively. It is seen that the strength of soil-resin mixture is decreased slightly in comparison with the strength of the natural soil $(280 \mathrm{kPa})$. The peak strength for curing time of 28 days is about $324 \mathrm{kPa}$, which shows an increase of about $16 \%$ compared with the natural soil. The peak strength values of soil-cement with $10 \%$ resin after curing times of 3,7 and 28 days are 274,300 and $467 \mathrm{kPa}$ at strains of $5 \%, 3.7 \%$ and $3.4 \%$, respectively. It is seen that for curing times of 3 and 7 days the variation of strength is insignificant in comparison with the natural soil, but after 28 days curing time the strength increases by about $67 \%$. It can be concluded from Figures 2 and 3 that the ductility of soil-resin samples is increased by the addition of resin. Figure 4 shows the effect of $5 \%, 8 \%$ and $10 \%$ resin on the behaviour of the soil after curing time of 28 days. The strength of the mixture increases with increasing resin content. The variations of compressive strength with different percentage of resin content for soil-resin mixture with different curing times (3, 7 and 28 days) are shown in Figure 5. The increase in strength is more obvious after 28 days. It can be concluded that the percentage of resin and curing time play important roles in increasing the strength of the soilresin mixtures.

Typical stress-strain curves for mixtures of soil-cement and

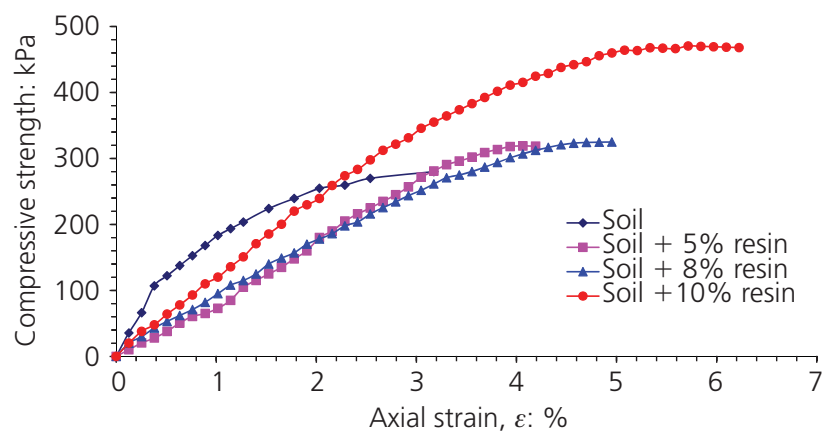

Figure 4. Stress-strain curves for soil and mixtures of soil with different percentages of resin after 28 days' curing time

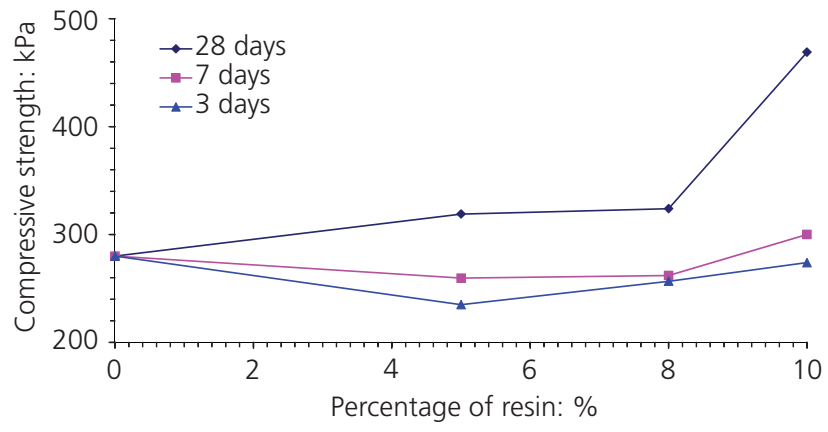

Figure 5. Variations of compressive strength with different percentages of resin for soil-resin mixture with various curing times

soil-cement-resin with $8 \%$ and $12 \%$ cement and $0 \%, 5 \%, 8 \%$ and $10 \%$ resin are shown in Figures 6 and 7 after curing times of 7 and 28 days, respectively. Figure 6 shows that the peak strengths of soil-cement and soil-cement with $5 \%$ resin after 7 days of curing are nearly the same $(1950-2000 \mathrm{kPa})$. The strength of mixtures of soil-cement with $8 \%$ and $10 \%$ resin is increased to 2250 and $2650 \mathrm{kPa}$ (Figure 6), respectively. Therefore, for a given curing time, the strength is increased with increase in the resin content. Figure 7 shows similar results for the mixtures of soil-cement and soil-cement-resin after 28 days of curing time. It is clear that the stress-strain curves are changed by increasing the resin content. Figure 7 shows that the strength of the soil-cement mixture is about $3160 \mathrm{kPa}$, but for the mixtures of soil-cement with $8 \%$ and $10 \%$ resin the strength is increased to 4090 and $4560 \mathrm{kPa}$, respectively. This shows the role of resin in increasing the strength of the mixture. These results are consistent with the findings reported by Anagnostopoulos et al. (2003) and Estabragh et al. (2011). It is observed from this figure that the initial slope of the stress-strain curves is increased by increasing the resin content. The variations of compressive strength of mixtures of soil-cement-resin with different resin contents, after curing times of 3, 7 and 28 days,

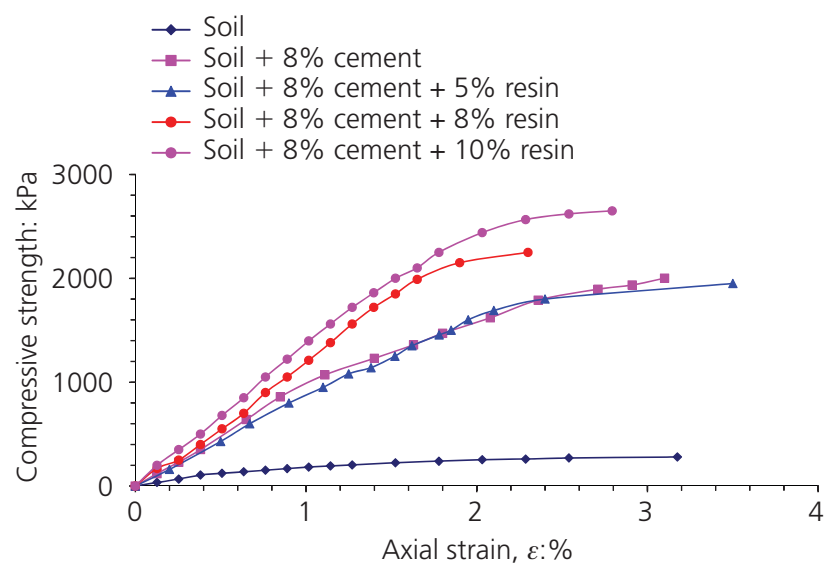

Figure 6. Stress-strain curves for soil and mixtures of soil-cement with different percentages of resin after 7 days' curing time 


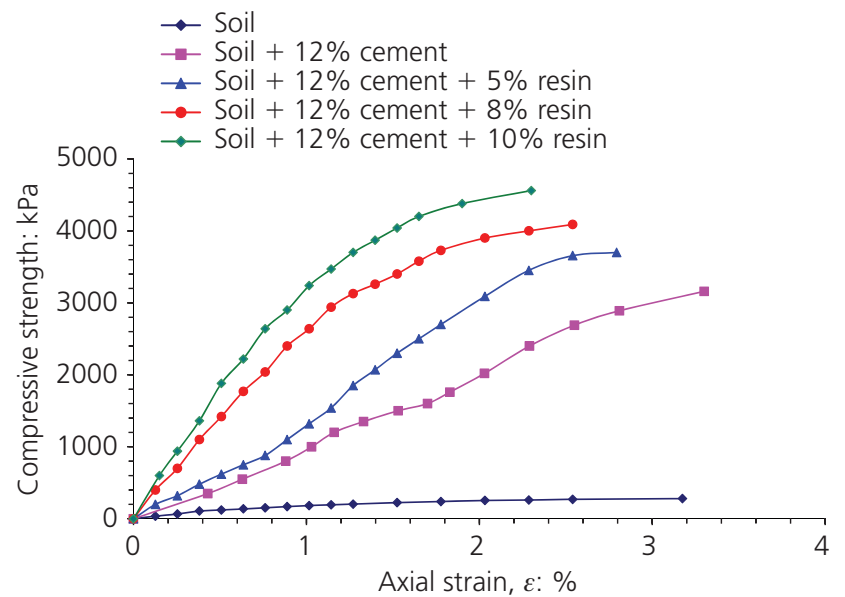

Figure 7. Stress-strain curves for soil and mixtures of soil-cement with different percentages of resin after 28 days' curing time

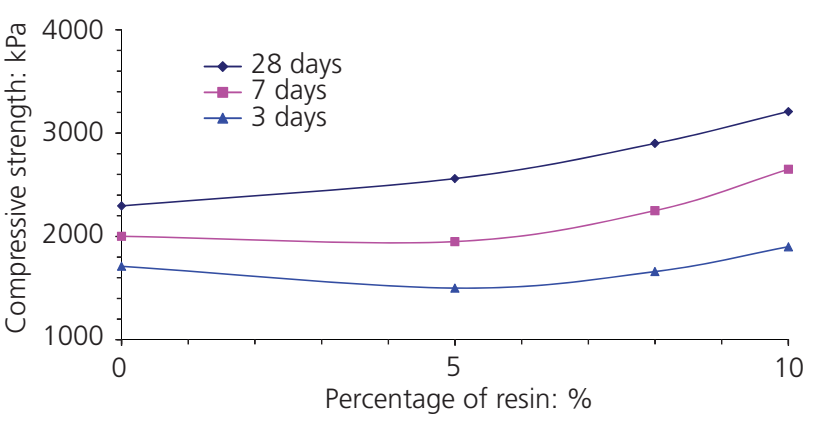

Figure 8. Variations of compressive strength with different percentages of resin for soil with $8 \%$ cement during various curing times

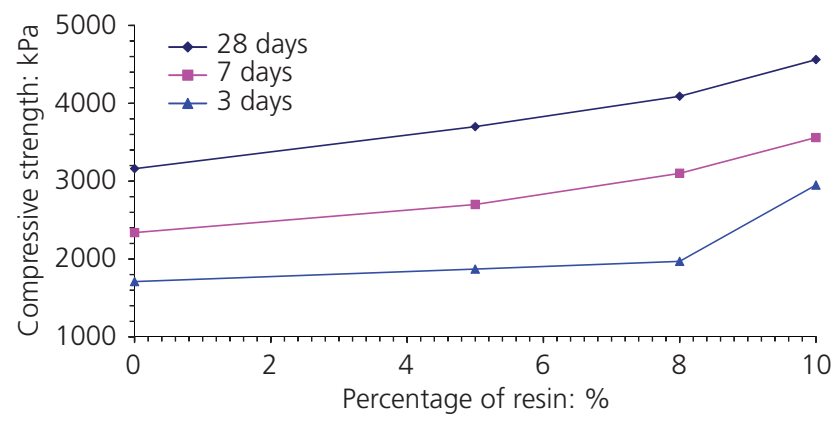

Figure 9. Variations of compressive strength with different percentages of resin for soil with $12 \%$ cement during various curing times

are shown in Figures 8 and 9 for $8 \%$ and 12\% cement, respectively. These figures indicate that besides the cement content, the percentage of resin and curing time are important factors in achieving the strength of the mixture. Figure 10 shows the

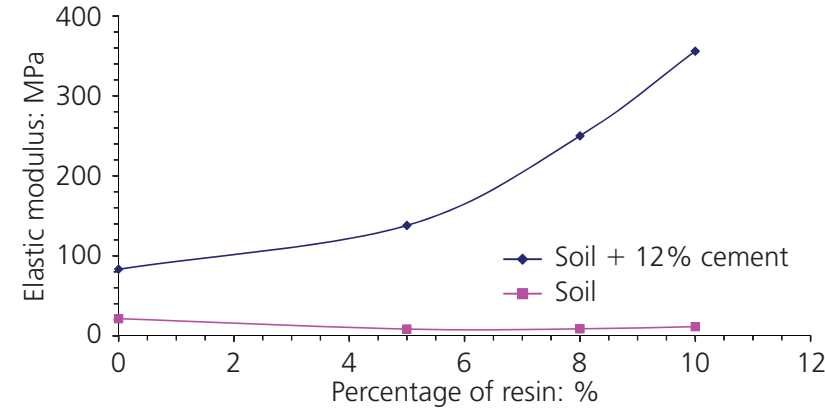

Figure 10. Variations of elastic modulus with different percentages of resin for soil and soil with $12 \%$ cement

variation of elastic modulus with different percentages of resin for the soil and mixture of soil with $12 \%$ cement. The elastic modulus was calculated on the basis of the $50 \%$ strength from the stress-strain curves. This figure shows that the value of elastic modulus for soil-cement increases with increasing percentage of resin; however, for the soil with resin, the variation of elastic modulus with resin content is insignificant.

The surfaces of clay particles carry negative charges, mainly as a result of isomorphous substitution or due to dissociation of hydroxyl. The negative charges result in cations present in the water in the void space being attracted to the particles. The cations are not held strongly and if the nature of the water changes they can be replaced by other cations, a phenomenon referred to as cation exchange. When they are mixed with resin, organic molecules undergo polymerisation reactions around the clay particles that bind the soil particles together. The process of attachment of clay particles to the polymer is caused by ion exchange reaction (Scholen, 1995). The results of tests on soilcement show that adding cement to soil produces a relatively high strength mixture. The strength of soil is increased by increasing the percentage of cement and the curing time. This can be attributed to the cementation between soil particles. During compaction of the soil-cement mixture, chemical bonds develop between adjacent cement grain surfaces and between cement and soil particle interfaces. In clay soils, the hydration of cement creates strong linkages between minerals and the aggregates to form a new fabric so that the particles cannot slide over one another (Estabragh et al., 2011). These linkages between soil and cement develop and complete in time. The final reaction between soil and cement causes the strength to increase and plasticity and water-holding capacity of clay soil to decrease (AlRawas et al., 2005).

The resins that were used in this study are from the acrylic family. The most numerous class of monomers are the acrylics, such as esters of acrylic acid and methacrylic acid. These acids are both crystalline solids at low ambient temperature, becoming liquid at slightly higher temperatures. They polymerise and copolymerise extremely rapidly and hence are frequently 
employed in copolymers to obtain alkali-soluble polymers. While both acids are water soluble, methacrylic acids, as might be expected because of its angular methyl group, is more soluble in ester monomers (Warson and Finch, 2001).

When water is added to the mixture of soil-cement and resin, the reaction of soil and cement occurs as described above. However, resin usually has a large amount of $\mathrm{COO}^{-}$, so it can react with $\mathrm{Ca}^{2+}$ because of hydrolysis in alkaline solution and produce $\mathrm{RCOO}^{-}$. The final reaction is as shown in Equation 1.

$$
\text { 1. } 2 \mathrm{RCOO}^{-}+\mathrm{Ca}^{2+} \rightarrow[\mathrm{RCOO}]^{-} \mathrm{Ca}^{2+}[\mathrm{OOCR}]^{-}
$$

The $[\mathrm{RCOO}]^{-} \mathrm{Ca}^{2+}[\mathrm{OOCR}]^{-}$is formed on the surface of $\mathrm{CSH}$ (calcium silicate hydrate) gel or $\mathrm{Ca}(\mathrm{OH})_{2}$ crystals. The interwoven network structure consists of ion-bonded large molecular systems which bridge by means of $\mathrm{Ca}^{2+}$ (Gao et al., 2002).

It is concluded from these experimental results that nontraditional chemical agents (resin) can increase the strength of soil and soil-cement mixtures. The resin reacts with soil and hydration products of cement and increases the strength through binding the particles and forming a rigid structure in the mixture. These agents can be used for treatment of cohesive soils for construction works such as subgrade and to provide material for erosion resistance where the existing soil is cohesive and limitations such as haulage distance of other soils and economic and environmental restrictions make the use of existing soil the preferred option. Durability tests should be carried out to study the long-term effects of resins and the environmental effects should be evaluated by considering the possible pollution caused by these agents under actual field conditions.

\section{Conclusion}

The aim of this research was to study the effects of resin in improving the mechanical behaviour of clay soil and soil-cement mixtures consisting of a clay soil with cement. The following conclusions can be drawn from the results of this work.

Both resin and cement, as non-traditional and traditional chemical agents, improve the strength of a clay soil. The effect of cement is greater than that of resin, but besides increasing the strength the resin also improves the ductility of the soil. The amount of improvement is a function of the proportions of the agents and the curing time.

- Addition of resin to a soil-cement mixture improves the properties of the mixture. For a given cement content this improvement is a function of percentage of resin and curing time. The initial slope of the stress-strain curves (stiffness) is increased by increasing the percentage of resin.

\section{REFERENCES}

Afridi UMK, Chaudhary ZU, Ohama Y, Dermura YK and Iqbal MZ (1994) Elastic properties of powder and aqueous polymer modified mortars. Cement and Concrete Research 24(7): 1199-1213.

Ajayi-Mejebi A, Grissom WA, Smith LS and Jones EE (1991) Epoxy resin-based chemical stabilization of a fine poorly graded soil system. Transportation Research Record 1295 : 95-108.

Al-Rawas AA, Hago A and Al-Sarmi H (2005) Effect of lime, cement and sarooj (artificial pozzolan) on the swelling potential of an expansive soil from Oman. Building and Environment 40(5): 681-687.

Anagnostopoulos CA (2007) Cement-clay grouts modified with acrylic resin methyl methacrylate ester: physical and mechanical properties. Construction and Building Materials 21(2): 252-257.

Anagnostopoulos CA and Hadjispyrou S (2004) Laboratory study of an epoxy resin in grouted sand. Ground Improvement 8(1): $39-45$.

Anagnostopoulos CA, Stavridakis I and Grammatikopoulos N (2003) Engineering behaviour of cement acrylic resin treated soft clay. Proceedings of International Conference on Problematic Soils, Trent University, Nottingham, UK, pp. $183-188$.

ASTM (1983) D1633: Standard test methods for compression strength of moulded soil-cement cylinders. ASTM, West Conshohocken, PA, USA.

Bahar B, Benazzoug M and Kenai S (2004) Performance of compacted cement stabilized soil. Cement and Concrete Composites 24(7): 811-820.

Bolander P (1999) Laboratory testing of non-traditional additives for stabilization of roads and trial surfaces. Transportation Research Record 1652: 24-31.

Broms BB and Boman P (1978) Stabilization of Soil with Lime Columns, Design Handbook, 2nd edn. Department of Soil and Rock Mechanics, Royal Institute of Technology, Stockholm, Sweden.

Croft JB (1967) The influence of soil mineralogical composition on cement stabilization. Géotechnique 17: 119-135.

Estabragh AR, Beytolahpour I and Javadi AA (2011) Effect of resin on the strength of soil-cement mixture. Journal of Materials in Civil Engineering 23(7): 969-976.

Gao JM, Qian CX, Wang B and Morino K (2002) Experimental study on properties of polymer-modified cement mortars with silica fume. Cement and Concrete Research 32(1): $41-45$.

Ingles OG and Metcalf JB (1972) Soil Stabilization. Butterworths, Sydney, Australia.

Katz LE, Rauch AF, Liljestrand HM, Shaw KS and Vieira AR (2001) Mechanisms of soil stabilization with liquid ionic stabilizer. Transportation Research Record 1757: 50-57.

Khair A, Nalluli C and Kilkenny WM (1991) Soil-cement tiles for lining irrigation canals. Irrigation and Drainage System 5(2): $151-163$.

Miller G and Azad S (2000) Influence of soil type on stabilization with cement kiln dust. Construction and Building Materials 14(2): 89-97. 
Mitchell JK (1976) Fundamentals of Soil Behaviour. Wiley, New York, NY, USA.

Rauch AF, Harmon JS, Katz LE and Liljestrand HM (2002) Liquid soil stabilizations: measured effects on engineering property of clay. Transportation Research Record 1757: $33-41$.

Scholen DE (1992) Nonstandard Stabilizers. Report FHWA-FLP92-011. FHWA, US Department of Transportation, Washington, DC, USA.

Scholen DE (1995) Stabilizer mechanisms in non-standard stabilizers. Proceedings of the 6th International Conference on Low-Volume Roads. TRB, National Academy Press, Washington, DC, USA, 252-260.
Sezer A, Inan G, Yimaz HR and Ramyar K (2006) Utilization of a very high lime fly ash for improvement of Izmin clay. Building and Environment 41(2): 150-155.

Tang C, Shi B, Gao W, Chen F and Cai Y (2007) Strength and mechanical behaviour of short polypropylene fiber reinforced and cement stabilized clay soil. Geotextiles and Geomembranes 25(3): 194-202.

Tingle JC and Santoni R (2003) Stabilization of clay soils with non-traditional additives Transportation Research Record 1819: $72-84$.

Warson H and Finch CA (2001) Applications of Synthetic Resin Latices, vol. 1, Fundamental Chemistry of Latices and Application in Adhesives. Wiley, Chichester, UK.

\section{WHAT DO YOU THINK?}

To discuss this paper, please email up to 500 words to the editor at journals@ice.org.uk. Your contribution will be forwarded to the author(s) for a reply and, if considered appropriate by the editorial panel, will be published as a discussion in a future issue of the journal.

Proceedings journals rely entirely on contributions sent in by civil engineering professionals, academics and students. Papers should be $2000-5000$ words long (briefing papers should be 1000-2000 words long), with adequate illustrations and references. You can submit your paper online via www.icevirtuallibrary.com/content/journals, where you will also find detailed author guidelines. 